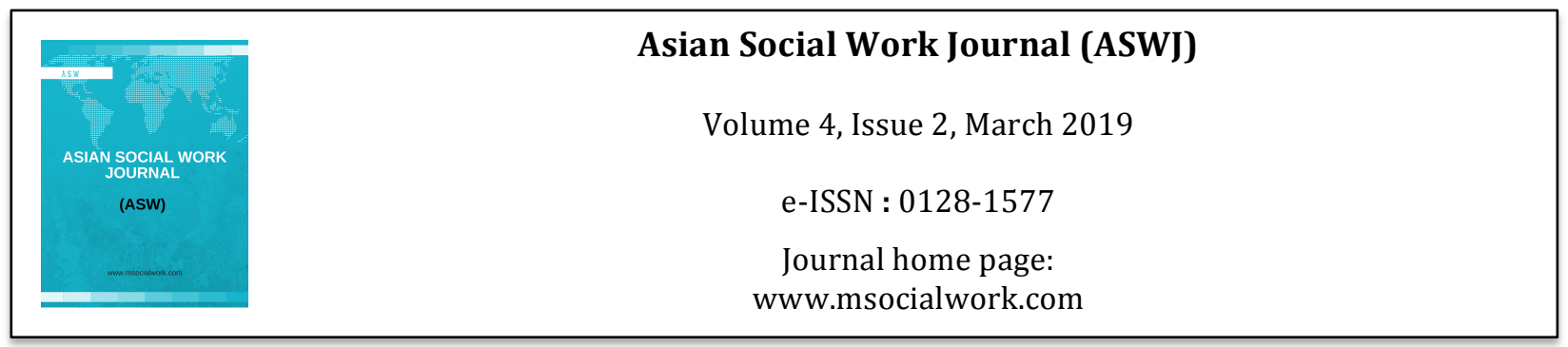

\title{
The Effect of Dhikrullah on Brain Health According to Neuroscience
}

\author{
Iskandar ${ }^{1}$, M. Dirhamsyah ${ }^{2}$ \\ ${ }^{1}$ Department of Counseling Guidance, Faculty of Ushuluddin Adab and Dakwah, Islamic Stte Institute (IAIN), \\ Malikussaleh Lhokseumawe, Indonesia \\ 2Faculty of Engineering, Syiah Kuala University, Indonesia \\ Corrrespondence: Iskandar (isibrahm@gmail.com)
}

\begin{abstract}
Dhikrullah according to verse 2 of chapter al-Anfal and verse 28 of chapter ar-Rad in the Koran has a vibrational effect on the calmness of the heart. Dhikrullah has been practiced by Muslims for more than a thousand years, but the explanation of the implications of the dhikrullah's vibration on human health from the neuroscience approach has yet to be completed. This study is an academic response to get scientific answers about the influence of dhikrullah on the health of the human brain. The attention of Islamic scholars to dhikrullah phenomena from the scientific approach is still far from hope, so the explanation of the effects of the dhikrullah's vibration on human mental health has not been completed. In this study, the authors used combined data, qualitative data from 4 respondents to find the model of dhikrullah and quantitative data from 10 subjects to obtain samples of brain waves through Electro Encephalo Graf (EEG) to see the effects of the dhikrullah on human brain waves. The results of the study show that the brain tends to adjust its frequency with the frequency of the sound stimulus it receives through the ear. Dhikrullah's vibration influences beta waves and alpha waves on the subject's brain waves while running the dhikrullah. According to EEG, dhikrullah is proven to be able to present alpha waves as a stimulus to neurotransmitters in the human brain to produce endorphins. Therefore, the authors conclude that this study is a new approach to see the process of the significance of the dhikrullah's vibration on human health. The United Nations, especially WHO, can use dhikrullah vibration as an approach to help human beings who need a solution from a spiritual approach permanently.
\end{abstract}

Key words: dhikrullah, brain health, neuroscience, human health

\section{Introduction}

Post-conflict and disaster in Aceh, left trauma in the memory of the victims' victims for different periods of time for each victim. These emotional recordings will have implications for the personality system of the victims. Therefore, based on a number of previous studies and the facts of the field, it is known that the amygdala experiences dynamics following the process and environment in which emotions develop. Young Waly in the past had benefits for mental therapy. Until now, no researcher, whether from academic or traditional circles, has examined the influence of Zikrullah on the emotional center of the amygdala from the scientific approach. This situation prompted researchers to ask why until now there had not been any among the Acehnese people who came forward to explain the influence of Zikrullah on the amygdala so that it could be an alternative method for mental therapy for 
the community. Paul Broca managed to find the center of sound activity in the human left brain ${ }^{1}$ ]. Bonnie R Strickland found that sound influences the nervous system. Alfred Tomatis found that sound gave an impression of brain waves. He managed to find a connection between sound frequencies that stimulate hearing. Carol Turkington see sound like a driving factor for emotional potential in memory. Larry Dossey found healing methods for healing words based on the influence of prayer. William Walker Atkinson proves that sound can affect mental states. Brigitte Stemmer and Harry A. Whitaker discovered sound waves can stimulate nerve cells. Bryan Kolb and Ian Q.

Whishaw proves that sound can affect neurons that function to control perception, hearing, memory, and speech. Carol Turkington Another important finding by Joe Kamiya in the 1960s expanded biofeedback in the interest of therapeutic techniques with alpha rhythm techniques using tones to show that the brain can produce alpha waves. Robert F. Hink found that in the brain there is one phenomenon of the frequency following response, which is a condition in which the brain tends to adjust its frequency with the frequency of stimulation of sound from the outside. James D'Angelo examines the strength of the letters contained in the verse of Allah. Iskandar examines the influence of dhikrullah on brain waves. Based on the objectives and benefits of the study of the relevance of the Prophet to the amygdala as the center of emotion in the human brain according to neuroscience review has a significant value in the context of finding a solution as well as a permanent contribution to the arrangement of modern human emotional disturbances which mainly increase alpha and endorphins as triggers brain. Systematics include the understanding of neuroscience, the understanding of dhikrullah, dhikrullah as a brain, brain stimulus, the influence of dhikrullah on the brain, amygdala, amygdala function, amygdala and personality, the influence of dhikrullah on amygdala and closing.

\section{Amygdala}

The study of the relationship between the Prophet and mentality of humans, especially the amygdala in the Southeast Asian region and the Islamic world, in general, is a new study, whereas in the West the problem has long been going on with different versions. The amygdala theory explains emotional dynamics in humans. The definition of amygdala comes from the Latin amygdalae, which is a nerve loop in the brain that plays a role in processing and reacting to emotions. Amygdala is a structure inside the temporal labus that stores and manages data emotionally. He controls human behavior when facing emotional conditions. It receives stimulation from visual and audio as a driving factor for emotional potential ${ }^{2}$. The condition of the amygdala affects the process of earning hormones, the circulatory system, breathing, and digestion in the hypothalamus. The hippocampus is a memory that controls data that is intellectual. In the limbic system, the hippocampus plays a central structure in the formation of emotions and memory. The hippocampus is related to memory strength. Based on the results of the study that the amygdala plays a role in feelings of fear and anxiety for humans ${ }^{3}$, the Amygdala is also involved in the process of adjusting various anatomical fields to obtain physiological responses to increased blood pressure, breathing and behavioral responses to fearful facial expressions. Amygdala has a relationship with hearing ${ }^{4}$. Therefore, dhikrullah can be one of the activities that vibrate emotions in the amygdala so that it can stimulate to shed tears when crying. Rough speech will be stored in the emotional memory of the amygdala in parts of the brain and will be recorded in memory for a long time. Involving spiritual emotions in an interaction with the aim of touching the memory of the amygdala will have implications for the emotional arrangement. Emotional development in the amygdala is influenced by a number of complex experiences that accompany all work and thought. In a depressed condition, the amygdala sends a message to the endocrine gland to secrete a number of chemicals that begin with the release of CRF (corticotrophin-releasing factor) and end with a flood of hormones kartisol. The buildup makes the amygdala a very sensitive detonator so that it can react more dominantly from rational considerations.

\footnotetext{
${ }^{1}$ A. P. Wickens, A History Of The Brain From Stone Age Surgery To Modern Neuroscience.

${ }^{2}$ V.S, R. (2002). Encyclopedia of Human Brain. Academic Press: USA.

${ }^{3}$ Ferry, B. (Teh Amygdala A Discrete Multitasking Manager). 2012. Croatia: In Tech.

${ }^{4}$ Masuda, A. (2004). Post-Genomic Perspective in Modeling and Control of Breathing. New York: Plenum Publishers.
} 


\section{Amygdala Function}

Amygdala will emit emotional reactions to the stimulus received in accordance with the emotional memory of an event or object. The emotional data processing center in the brain will fill in new data or allow the data to affect the amygdala. Emotions can be understood as individual turmoil accompanied by a response to a stimulus that contains a basic need where if these needs can be met, then feel happy and if not angry. Amygdala which occupies the main position as a memory element that records emotional experiences in the limbic system when there is a process of internal and external interaction in humans continues to get the attention of neuroscience experts ${ }^{5}$. They argue that according to a number of studies that have been carried out on the amygdala show a significant role in activating the emotional system when interactions occur. The expert perspective on the position of the amygdala can be seen in the opinion of Lisa Feldman who has conducted a study of amygdala with the result that the size of the amygdala is related to the ability to socialize adults on a complex scale ${ }^{6}$. While the amygdala in the view of neurotheology states fundamentalist anti-rationalist religious behavior is caused by very strong neurological activity in a part of the brain of the limbic system in the human brain. Paul Sanberg found the amygdala also has a role in the presence of fear, emotions, and even seizures that we have. According to the neuroscientist Joseph Le Doux, the amygdala in the human brain functions as a storage place for memory related to emotions. Amygdala will react according to the emotional experience she has experienced, whether it is a pleasant experience or not. In individuals whose amygdala is disturbed, they become less interested in other individuals and the personality condition becomes passive accompanied by an introduction to emotions from an affective blindness.

\section{Neuroscience}

Neuroscience is a field of science with various approaches that specialize in scientific studies of the nervous system, among others, it aims to explain human behavior from the viewpoint of the activities that apply to the brain $^{7}$. The brain which consists of millions of neuron individual nerve cells can produce behavior. Among other things, Neuroscience involves the structure, function, evolutionary history, formation and development, genetics, biochemistry, physiology, pharmacology, information flow, memory and pathology of the system. At present, there have been many research collaborations between disciplines within the framework of neuroscience, such as psychology-neuro and cognitive disciplines, computer science, statistics, physics, and medicine ${ }^{8}$. Neuroscience can help explain emotional and intellectual phenomena in humans to all interested parties. The most important explanation is about the most appropriate model to foster a paradigm as the principle of human thinking ${ }^{9}$. Therefore, the importance of the role of neuroscience needs to be addressed by all parties, especially those involved in education, to better understand the learning process. This understanding may help the education system move to make the right decisions to develop expertise. Neuroscience provides information about the human brain and how to respond to different learning than the environment. This understanding is for education because there are so many statements about self and the environment that are blocked to be known for sure.

\section{Brain}

Brain theory explains the function of these organs as a control center for human emotional awareness. The brain is a system that controls the body and all human activities. In the brain, there are neurons which are the basic units that regulate communication and information. Neuron cells can convert received data into electrical impulses through a series of depolarization processes ${ }^{10}$. Each neuron has branches of dendrites and axons. Dendrites have a very important function to receive stimuli including

\footnotetext{
5 Mubarok, A. (2001). Psikologi Qur`ani. Jakarta: Pustaka firdaus.

${ }^{6}$ Hawari, D. (1997). Do`a dan Dzikrullah . Jakarta: Dana Bakti Primayasa.

7 Elfiky, I. (2009). Terapi berpikir positif.

8 A Lexander T Odorov, S. U. (2010). Social Neuroscience.

9 Dossey, L. (Healing Words : The Power OF Prayer and Teh Practice of Medicine). 1993. San Fransisco: Harper San Fransisco.

10 C.Oreilly, R. (2000). Making Magic : Religion. Magic. and Sience in The Modern World. USA: Oxford University
} 
those related to the stimulus process (cognitive). When the brain gets stimulated, neuron cells can produce new dendritic branches to improve communication between brain cells and indirectly make the brain smarter than before. Dendrite is still produced by the brain even in old age ${ }^{11}$. Sensory neurons receive signals from recipients (receptors) from the eyes, skin, muscles, joints, and organs. Each neuron receives electrical impulses through dendrites. Sufficient stimulus to the neuron will produce an impulse to the axon that connects through synapses to other dendritic cells ${ }^{12}$. The frequency of human brainwaves depends on the stage of human consciousness. Beta waves $(13-30 \mathrm{~Hz})$ indicate the mind is in a state of focus, alertness, and analysis. Alpha waves $(8-13 \mathrm{~Hz})$ indicate that the mind is in a calm state, more dominant feeling, visualization, creative and not receiving sensory input ${ }^{13}$. Alpha waves are used by hypnologists to provide a trace effect (empty mind).

\section{Results And Discussion}

Allah has declared His Names specifically in the Koran which can be called repeatedly. Remembrance can be done by calling Allah ... Allah ... with the tongue continuously and giving full attention to remembrance. Remembrance can also be done by remembering and repeating the name of Allah. Therefore, Zikrullah is to repeat the name of Allah (Recollection of God). How to call can be done in a voice with the tongue repeating the name of God. Zikrullah can also be done with a single remembrance (al-dhikr al-mufrad), that is, only mentioning the Name of Allah (the mention of the name Allah alone).

\section{Zikrullah as a Brain Stimulus}

Allah has declared His Names specifically in the Koran Allah has declared His Names specifically in the Koran which can be called the Process of Allah starting from the brain. therefore, exploring dhikrullah from a science perspective will relate to an explanation of the brain. The brain weighs between 1100 and $2000 \mathrm{~g}$ and contains around 100 billion neurons. The brain functions to connect between the micro-nature in man and the macro nature outside of the human self. Internally, neurons can communicate with each other through the emission of electric waves produced. The brain produces waves that can radiate outward and can cause the influence of communication on the environment. In the process of interaction, the brain has the potential to receive interference from various waves originating from outside itself. Disorders of brain waves will cause the body's control system to not function optimally and influence the metabolic system and other nerves in the body. In the left brain, there is a temporal lobe where wernicke functions as an area to begin the initial process of speaking before being sent to broka located in the frontal lobe. Although dhikrullah starts from wernicke, the left part of the brain, it is related to the limbic system (limbic system) which can receive stimulation visually and audio. The limbic system as the location of emotional memory located in the center of the brain as a human control center issues emotional and rational commands related to various other organs in the human body. Therefore, the brain issues command from the Prophet, both emotional and rational. The emotional and rational commands relate to other organs in the human body. The effect of the dhikrullah wave on the brain will also guard the pulse of the heart, guard blood stress, and maintain body fluid balance and body temperature.

Dhikrullah is produced from the vibrations of the air on the vocal cords caused by energy. When mentioning the name of Allah, Power creates vibrations in the vocal cords that cause air in the oral cavity to vibrate to produce sound. This is an event of resonance that is because God's name can be heard. The oral cavity also functions as a resonator, which is an air space that serves to strengthen the sound. The waves of dhikrullah that enter the ear are converted into electrical signals on the cochlea, then through the auditory, they are passed to the auditory cortex. The eardrum vibrates because the sound vibrations that enter the ear are one of the resonance events. When the name Allah is called, the

11 David Perlmutter, M. (2004). The Better Brain. New York: Riverhead Books.

12 Turkington, C. (2002). The Encyclopedia of The brain And Brain Disorder. 2002: An imprint of Infobase publishing

13 J.Hirsch, L. (2010). Atlas of EEG in Critical Care. U.K: Jhon Wiley \& Sons, Ltd. 
sound goes into the ear to the brain. Humans also hear and feel sounds through the skin and bone conduction, the sense of sight, smell, touch, and taste which allows humans to experience various vibrations more broadly through vibrations that are only captured by hearing. Therefore, humans are sensitive to sound. The sound waveform is a longitudinal waveform. Humans can produce sound through activities that apply to the vocal cords which are the main components in the sound generator besides the lungs and articulators. One form of sound therapy that is not applied through hearing is called cymatic therapy (cymatic therapy). The therapy uses a device that can send sound waves that can be heard continuously into the body through the skin. This process is said to introduce healing in the body. Sound can influence human behavior. Dossey admitted about spiritual symbols and sacred sources, but still not crowded scientists who use modern science to develop the role of sound for humans. Modern studies have succeeded in getting a voice as alternative energy in the future, along with renewable energy. The power produced by sound vibrations when through a medium is called sound energy. Sound energy is a type of mechanical power that is easily recognized through hearing. Sound power is represented visually as a wave. Following scientific theory, each vibration can produce sound energy in the form of energy waves.

Sound pollution that occurs a lot can cause disturbances in the brain and health, namely stress, disturbances in hearing or high blood pressure have been successfully engineered for the benefit of humans. Sound as an energy that can be heard turns out to benefit many people. Waves will bring energy, whether they can be seen or not. Sound waves can carry large amounts of energy. The amplitude of the wave is related to the energy carried by the wave. Strong sound waves have a greater amplitude than weak sound waves. Strong sound brings more energy than slow sound. Strong sound can bring enough energy to damage human hearing. The amount of energy contained by the wave follows the amplitude. For sound wave waves, the amplitude is related to how molecules are scattered. Sound pollution that occurs a lot can cause disturbances in the brain and health, namely, stress, hearing disorders or high blood pressure have been successfully engineered for the benefit of humans. Sound as an energy that can be heard turns out to benefit many people. Waves will bring energy, whether they can be seen or not. Sound waves can carry large amounts of energy. The amplitude of the wave is related to the energy carried by the wave. Strong sound waves have a greater amplitude than weak sound waves. Strong sound brings more energy than slow sound. Strong sound can bring enough energy to damage human hearing. The amount of energy contained by the wave follows the amplitude. For sound wave waves, the amplitude is related to how molecules are scattered.

\section{The Effect of Zikrullah on Amygdala}

Humans have two memories, namely the amygdala and hippocampus. Both memories are found in the limbic system in the brain. The limbic system consists of the thalamus which regulates sedar function and begins the process of data deria received by the body from outside the body before the data is sent to the cortex to produce a response. The hypothalamus controls the balance of bodily functions, through autonomic nerves guarding the heartbeat, blood stress, body temperature, participant behavior and emotions. Hippocampus is a memory for intellectual processes that have relevance to deria, especially the hearing and limbic cortex for the dhikrullah. The limbic system stores a lot of information and functions to control the human consciousness system. While the first girus functions to connect the emotional regulator in the limbic system with cognitive abilities in the skin of the brain (cerebral cortex). The mamilari regulates the movements of the tongue and the muscles of the esophagus when it is dhikrullah.

Amygdala stores emotional memory and regulates human behavior when facing certain conditions and also receives stimulation from visual and audio as a motivating factor for emotional potential. Amygdala affects hormone production, blood circulation, breathing, and digestion. Amygdala affects hormone production, blood circulation, breathing, and digestion. Because the Prophet influences brain waves, the influence of the Prophet on brain waves affects the amygdala. The condition of the amygdala has an effect on correcting breathing. A previous study of the differences in personality in the respiratory pattern when the soul was in a state of stress and physical burden found that the level of individual anxiety affected the respiratory frequency. Zikrullah's energy is able to harmonize the limbic system, the lobe in the head, the work of the heart, blood circulation and the lungs which are important 
elements as determinants of the state of psychological health. When performing the dhikrullah, the bioelectrical flow in the auditory nerve, memory, amygdala, and hippocampus in the brain becomes increased due to the active involvement of these parts in the process of the Prophet Muhammad. Likewise, if the Prophet is practiced repeatedly, the bio-electric flow will become more active. The active nerve will affect the other nerve groups to be active, so that the brain becomes active as a whole, resulting in waves caused by the Prophet. According to the Koran, the power of dhikrullah can lead someone to glory (Q. 62: 10).

These findings prove that scientifically, the Prophet Mohammed conducted repeatedly will improve the health quality of the brain. Zikrullah has a connection with human feelings for the amygdala. Therefore, sound waves, both during speaking and laughing are expressions of human emotions themselves. Therefore, it can be understood that a lot of doing dhikrullah can influence the brain. Zikrullah will also produce harmonious brain waves as mental signals are in a stable state. Mental support from stable brain waves can lead someone to be more prepared to deal with various things. It seems that there is a close relationship between stable brain waves with a stable mentality, where the stability of the two aspects is a condition to get the stable behavior. The special aspect of the human voice is that there is a cathartic function, that is, it can eliminate various influences on the mind which can cause disturbances in emotions. Therefore, the pronunciation of dhikrullah by following the methods of science is proven to produce more real implications if it produces a sound wave that is harmonious between belief and mind. The sound produced by a person can influence the nervous system in themselves and others. In each voice, there are various feelings. The sound is one of the main aspects to recognize a person's character and emotional state, as well as sadness or joy. Individual characters can be categorized by listening to the level of frequency, speed, and strength rather than sound, spoken language, how to sing or vocals used. If the voice has a different character between someone and another, so also with brain waves that have different characters between someone and the other. The sound produced by a person can influence the nervous system in themselves and others. In each voice, there are various feelings. The sound is one of the main aspects to recognize a person's character and emotional state, as well as sadness or joy. Individual characters can be categorized by listening to the level of frequency, speed, and strength rather than sound, spoken language, how to sing or vocals used. If the voice has a different character between someone and another, so also with brain waves that have different characters between someone and the other.

\section{Amygdala and Personality}

As David, a bourne explained that there is a relationship between the amygdala and the cortex. The age of 12 years is more dominant in developing the structure of the amygdala, while the cortex develops at the age of 20 years, therefore the amygdala develops earlier than the cortex. Caroline leaf explained in Who Switched Off My Brain that people who think well will experience an increase in the number of bonds of each neuron and dendrite in the brain more and regularly, while the brain that thinks negatively tends to damage brain cells. This damage is not only caused by stress factors and mental disorders, but also external factors due to hearing harsh words and negative influences from their environment. The designation aspect is what explains the procedure for mentioning dhikrullah which can affect the amygdala. Internal aspects of intention can have implications for changes in brain waves as a sign of change in emotions.

\section{Conclusion}

In the midst of the perspective debate among ulama regarding the practice of dhikrullah and the contradiction of methods of mental rehabilitation between volunteers from outside the country and local communities in Aceh, the researchers used a scientific approach to explore the benefits of the dhikrullah on the amygdala. Therefore, research on the effects of dhikrullah on the amygdala as an emotional center in the human brain according to neuroscience review will be an alternative solution for mental therapy and for activists of mental rehabilitation. The researcher chose the dhikrullah model because it was more in line with the interests of therapy and the situation of the victims in the field. Information about how to run the dhikrullah is needed in order to find out accordingly for the needs of 
the victim's therapy. The government can involve itself by adopting the results of this research into public policy to be used as social capital that can support the application of Islamic values in Aceh. The government has the authority to recommend mental hospitals, prisons, nursing homes, trauma rehabilitation centers, and drug rehabilitation centers to apply dhikrullah as therapy.

\section{Acknowledgement}

Thank you to Dr. Ridwan Muhammad Hasan as the contributor to the suggestion from the Postgraduate of UIN Ar-Raniry Banda Aceh

\section{References}

A Lexander T Odorov, S. U. (2010). Social Neuroscience.

C.Oreilly, R. (2000). Making Magic : Religion. Magic. and Sience in The Modern World. USA: Oxford University.

David Perlmutter, M. (2004). The Better Brain. New York: Riverhead Books.

Dossey, L. (Healing Words : The Power OF Prayer and Teh Practice of Medicine). 1993. San Fransisco: Harper San Fransisco.

Elfiky, I. (2009). Terapi berpikir positif.

Ferry, B. (Teh Amygdala A Discrete Multitasking Manager). 2012. Croatia: In Tech.

Hawari, D. (1997). Do`a dan Dzikrullah . Jakarta: Dana Bakti Primayasa.

J.Hirsch, L. (2010). Atlas of EEG in Critical Care. U.K: Jhon Wiley \& Sons, Ltd.

Masuda, A. (2004). Post-Genomic Perspective In Modeling and Control of Breathing . New York: Plenum Publishers.

Mubarok, A. (2001). Psikologi Qur`ani. Jakarta: Pustaka firdaus.

Turkington, C. (2002). The Encyclopedia of The brain And Brain Disorder. 2002: An imprint of Infobase Publishing .

Wickens, A. P. (n.d.). A History Of The Brain From Stone Age Surgery To Modern Neurosience .V.S, R. (2002). Encyclopedia of Human Brain. Academic Press: USA. 